\title{
Absorption and Emission Spectrum of $\left[\mathrm{Zn}_{4} \mathrm{O}(\text { Acetate })_{6}\right]$ Horst Kunkely and Arnd Vogler* Institut für Anorganische Chemie der Universität Regensburg, Universitätsstr. 31, D-8400 Regensburg, Federal Republic of Germany \\ The electronic spectrum of $\left.\left[\mathrm{Zn}_{4} \mathrm{O} \text { (acetate }\right)_{6}\right]$ in solution is characterized by an absorption $\left(\lambda_{\max }=216 \mathrm{~nm}\right)$ and emission $\left(\lambda_{\text {max. }}=372 \mathrm{~nm}\right.$ ) band; it is assigned to a ligaind-to-metal charge-transfer (LMCT) transition, which corresponds to the band-gap transition of the semiconductor $\mathrm{ZnO}$.
}

In recent years very small semiconductor particles have been studied extensively. The decrease of particle size is associated with a change of the optical properties (quantum size effect) that are different from those of the bulk semiconductor. ${ }^{1} \mathrm{~A}$ further reduction of the particle size would ultimately yield molecular dimensions. The optical properties of such molecular clusters which could be considered as being the smallest constituents of a semiconductor should be of considerable interest. We explored this possibility and selected the compound $\left.\left[\mathrm{Zn}_{4} \mathrm{O} \text { (acetate) }\right)_{6}\right]$ as a molecular model for $\mathrm{ZnO}$. While the optical properties of $\mathrm{ZnO}$ have been studied in detail, ${ }^{2}$ the electronic spectra of $\left.\left[\mathrm{Zn}_{4} \mathrm{O} \text { (acetate) }\right)_{6}\right]$ are as yet unknown. This complex seems to be well suited as a model for $\mathrm{ZnO}$ since the important structural features of both compounds are very similar. ${ }^{3,4}$ A tetrahedron of four $\mathrm{Zn}^{2+}$ ions contains an oxide ion. $\mathrm{Zn}^{2+}$ is also co-ordinated tetrahedrally by oxygen. In the case of the complex the tetrahedral co-ordination of $\mathrm{Zn}^{2+}$ by oxygen is achieved by the central oxide and three bridging acetate groups. Even the $\mathrm{Zn}-\mathrm{O}(c a$. 1.97) and $\mathrm{Zn}-\mathrm{Zn}(3.20 \AA)$ bond distances for both compounds are almost identical.

The complex $\left[\mathrm{Zn}_{4} \mathrm{O}(\text { acetate })_{6}\right]$ is soluble in a variety of solvents such as benzene, $\mathrm{CH}_{2} \mathrm{Cl}_{2}$, and ethanol. The solvents have to be completely dry in order to avoid hydrolysis with the formation of $\mathrm{ZnO}$. A complete spectrum of $\left.\left[\mathrm{Zn}_{4} \mathrm{O} \text { (acetate) }\right)_{6}\right]$ (Figure 1) was recorded in ethanol which is transparent above $200 \mathrm{~nm}$. The complex displays an absorption maximum at $\lambda=$ $216 \mathrm{~nm}\left(\varepsilon=62200 \mathrm{~mol}^{-1} \mathrm{dm}^{3} \mathrm{~cm}^{-1}\right)$. Absorption spectra of $\mathrm{Zn}$ (acetate $)_{2}$ in ethanol and $\mathrm{Zn}(\mathrm{OH})_{4}{ }^{2-}$ in water were also measured. These compounds did not show any absorption maximum above $200 \mathrm{~nm}$.

Solutions of $\left.\left[\mathrm{Zn}_{4} \mathrm{O} \text { (acetate }\right)_{6}\right]$ emitted an intense photoluminescence at room temperature. In $\mathrm{CH}_{2} \mathrm{Cl}_{2}$ the luminescence appeared at $\lambda_{\max .}=372 \mathrm{~nm}$ (Figure 1). At $\lambda_{\mathrm{exc}}$ $=300 \mathrm{~nm}$ the quantum yield of emission was $\phi=0.15$. 


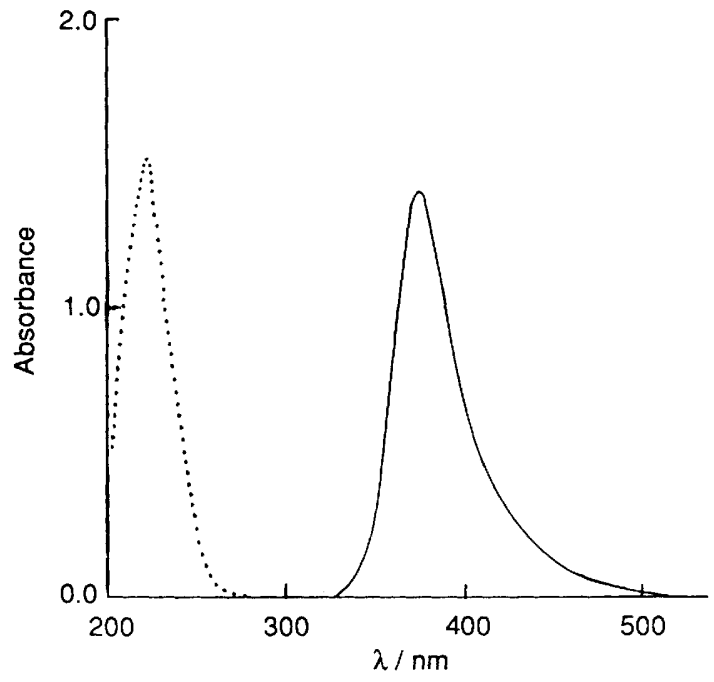

Figure 1. Electronic absorption $(\cdots)$ ) and emission $(-)$ spectra of [ $\mathrm{Zn}_{4} \mathrm{O}$ (acetate $\left.)_{6}\right]$ at room temperature; $1 \mathrm{~cm}$ cell. Absorption: 2.43

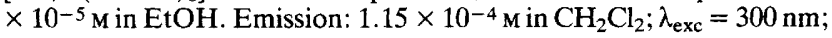
intensity in arbitrary units.

The emission decayed with a life time of approximately $\tau=10 \mathrm{~ns}$. The excitation spectrum of $\left.\left[\mathrm{Zn}_{4} \mathrm{O} \text { (acetate }\right)_{6}\right]$ in ethanol was in good accord with the absorption spectrum. Solutions of $\mathrm{Zn}$ (acetate) $)_{2}$ or $\mathrm{Zn}(\mathrm{OH})_{4}{ }^{2-}$ did not show any photoluminescence.

Simple $\mathrm{Zn}^{2+}$ complexes such as $\mathrm{ZnX}_{4}{ }^{2-}$ with $\mathrm{X}=$ halide $^{5}$ or $\mathrm{OH}^{-}$do not show ligand-to-metal charge-transfer (LMCT) absorptions above $200 \mathrm{~nm}$. The energy of the $\mathrm{Zn}^{2+} 4 \mathrm{~s}$ orbital which is the acceptor orbital of a LMCT transition is apparently too high. On the contrary, the semiconductor $\mathrm{ZnO}$ absorbs at $\lambda_{\text {os }} \leqslant 365 \mathrm{~nm}$ (os $=$ onset of absorption). ${ }^{1,2}$ In a molecular picture ${ }^{2}$ this band-gap transition can be also considered as being an LMCT transition since the valence band of $\mathrm{ZnO}$ is composed of the filled oxide valence orbitals while the conduction band is formed by the empty $\mathrm{Zn}^{2+} 4 \mathrm{~s}$ orbitals. The energy of the LMCT transition is expected to decrease as the number of the interacting valence orbitals at oxide and $\mathrm{Zn}^{2+}$ increases. Accordingly, a red shift of the band-gap transition is observed if the particle size increases from the smallest quantum size particles $\left(\lambda_{\text {os }} c a .310 \mathrm{~nm}\right)$ to bulk $\mathrm{ZnO} .^{1,2}$ The electronic structure and the absorption spectrum of the molecular cluster can now be explained by using the same model.

The interaction of the four $\mathrm{Zn}^{2+} 4$ s orbitals of $\left[\mathrm{Zn}_{4} \mathrm{O}\right.$ (acet- ate) 6 ] generates a bonding $a_{1}$ and three degenerate antibonding $t_{2}$ MOs (in $\mathrm{T}_{\mathrm{d}}$ symmetry). ${ }^{6} \mathrm{~A}$ similar interaction of the valence orbitals of the co-ordinating oxygen atoms should take place but is complicated by the fact that these oxygen atoms originate from the central oxide and the peripheral acetate ligands. In agreement with our qualitative model the oxide to $a_{1}\left(\mathrm{Zn}^{2+}\right)$ LMCT transition $\left(\lambda_{\max .}=216 \mathrm{~nm}\right)$ occurs at lower energies than that of mononuclear oxygen co-ordinated $\mathrm{Zn}^{2+}$ complexes [e.g. $\mathrm{Zn}(\text { acetate })_{2}$ or $\mathrm{Zn}(\mathrm{OH})_{4}{ }^{2-}$ ] but at higher energies than the band-gap absorption of $\mathrm{ZnO}$ particles which contain a much larger number of $\mathrm{Zn}^{2+}$ and oxide ions.

The luminescence properties are also quite interesting and informative. While mononuclear $\mathrm{Zn}^{2+}$ complexes have not been observed to show any emission (with the exception of a ligand-localized luminescence of $\mathrm{Zn}^{2+}$ complexes with ligands such as porphyrins ${ }^{7}$ or $2,2^{\prime}$-bipyridyl ${ }^{8}$ ) the LMCT state of $\left.\left[\mathrm{Zn}_{4} \mathrm{O} \text { (acetate) }\right)_{6}\right]$ luminesces strongly at $\lambda_{\max .}=372 \mathrm{~nm}$. The corresponding band-gap emission of $\mathrm{ZnO}$ occurs between $\lambda_{\text {max. }}=320 \mathrm{~nm}$ for small quantum size particles and $\lambda_{\max .}=$ $380 \mathrm{~nm}$ for the bulk. ${ }^{2}$ The Stokes shift of the band-gap emission is very small since the electronic excitation of a semiconductor particle does not involve structural rearrangements. On the contrary, the Stokes shift $\left(\Delta \bar{v}=19415 \mathrm{~cm}^{-1}\right)$ of the luminescence of $\left.\left[\mathrm{Zn}_{4} \mathrm{O} \text { (acetate }\right)_{6}\right]$ is rather large. A considerable excited-state distortion of the molecular cluster may occur because the LMCT transition leads to the population of the bonding $a_{1}$ orbital. Similar interpretations were used to explain the emission behaviour of tetranuclear complexes of the $\mathrm{d}^{10}$ metals $\mathrm{Cu}^{\mathrm{I}},{ }^{9} \mathrm{Ag}^{\mathrm{I}},{ }^{6} \mathrm{Au}^{\mathrm{I}},{ }^{10}$ and $\mathrm{Hg}^{\mathrm{II}} .{ }^{11}$

This work was supported by the Deutsche Forschungsgemeinschaft and the Fonds der Chemischen Industrie.

\section{Received, 11th June 1990; Com. 0/02614J}

\section{References}

1 A. Henglein, Top. Curr. Chem., 1988, 143, 113.

2 D. W. Bahnemann, C. Kormann, and M. R. Hoffmann, J. Phys. Chem., 1987, 91, 3789, and references cited therein.

3 H. Koyama and Y. Saito, Bull. Chem. Soc. Jpn., 1954, 27, 112.

4 S. C. Abrahams and J. L. Bernstein, Acta Crystallogr., Sect. B, $1969,25,1233$.

5 B. D. Bird and P. Day, J. Chem. Soc., Chem. Commun., 1967, 741.

6 A. Vogler and H. Kunkely, Chem. Phys. Lett., 1989, 158, 74.

7 M. Gouterman, in 'The Porphyrins,' ed. D. Dolphin, Academic Press, New York, 1978, vol. 3, p. 1.

8 T. Ohno and S. Kato, Bull. Chem. Soc. Jpn., 1974, 47, 2953.

9 A. Vogler and H. Kunkely, J. Am. Chem. Soc., 1986, 108, 7211.

10 A. Vogler and H. Kunkely, Chem. Phys. Lett., 1988, 150, 135.

11 H. Kunkely and A. Vogler, Chem. Phys. Lett., 1989, 164, 621. 